Edwin H. G. Oei

Ingrid M. Koster

Jan-Hein J. Hensen

Simone S. Boks

Harry P. A. Wagemakers

Bart W. Koes

Dammis Vroegindeweij

Sita M. A. Bierma-Zeinstra

M. G. Myriam Hunink

\section{MRI follow-up of conservatively treated meniscal knee lesions in general practice}

Received: 23 June 2009

Revised: 6 October 2009

Accepted: 8 October 2009

Published online: 17 November 2009

(C) The Author(s) 2009.

This article is published with open access at

Springerlink.com

E. H. G. Oei · M. G. M. Hunink ( $₫)$

Program for the Assessment

of Radiological Technology (ART

Program), Erasmus MC,

University Medical Center Rotterdam,

Room Ee21-40a, Dr. Molewaterplein 50,

3015 GE Rotterdam, The Netherlands

e-mail: m.hunink@erasmusmc.nl

Tel.: +31-10-7043391

Fax: +31-10-7044657

Present address:

E. H. G. Oei - I. M. Koster .

M. G. M. Hunink

Department of Radiology,

Erasmus MC,

University Medical Center Rotterdam, s-Gravendijkwal 230,

3015 CE Rotterdam, The Netherlands

E. H. G. Oei - M. G. M. Hunink

Department of Epidemiology,

Erasmus MC,

University Medical Center Rotterdam,

Dr. Molewaterplein 50,

3015 GE Rotterdam, The Netherlands
S. S. Boks $\cdot$ H. P. A. Wagemakers

B. W. Koes - S. M. A. Bierma-Zeinstra

Department of General Practice,

Erasmus MC,

University Medical Center Rotterdam,

Burgemeester s' Jacobplein 51,

3015 CA Rotterdam, The Netherlands

I. M. Koster · J.-H. J. Hensen •

S. S. Boks - D. Vroegindeweij

Department of Radiology,

Maasstad Ziekenhuis,

Olympiaweg 350 ,

3078 HT Rotterdam, The Netherlands

Present address:

S. S. Boks

Department of Radiology,

Diaconessenhuis Meppel,

Hoogeveenseweg 38,

7943 KA Meppel, The Netherlands

\begin{abstract}
Objective: To evaluate meniscal status change on follow-up MRI after 1 year, prognostic factors and association with clinical outcome in patients with conservatively treated knee injury. Methods: We analysed 403 meniscal horns in 101 conservatively treated patients ( 59 male; mean age 40 years) in general practice who underwent initial knee MRI within 5 weeks of trauma. We performed
\end{abstract}

ordinal logistic regression analysis to analyse prognostic factors for meniscal change on follow-up MRI after 1 year, and we assessed the association with clinical outcome. Results: On followup MRI 49 meniscal horns had deteriorated and 18 had improved. Age (odds ratio [OR] 1.3/decade), body weight (OR 1.2/10 kg), total anterior cruciate ligament $(\mathrm{ACL})$ rupture on initial MRI (OR 2.4), location in the posterior horn of the medial meniscus (OR 3.0) and an initial meniscal lesion (OR 0.3 ) were statistically significant predictors of meniscal MRI appearance change after 1 year, which was not associated with clinical outcome. Conclusion: In conservatively treated patients, meniscal deterioration on follow-up MRI 1 year after trauma is predicted by higher age and body weight, initial total ACL rupture, and location in the medial posterior horn. Change in MRI appearance is not associated with clinical outcome.

Keywords Knee - Trauma · Meniscus - Magnetic resonance imaging - Conservative treatment . Follow-up

\section{Introduction}

Traumatic knee injury is a frequently encountered condition with a reported incidence of 5.3 per 1,000 patients in Dutch general practice annually [1]. In our country, approximately $75 \%$ of patients with traumatic knee injury are diagnosed and treated conservatively by general practitioners. Most of these patients recover without the need for referral to a specialist or surgery [2].

Magnetic resonance imaging (MRI) is a well-established and accurate diagnostic imaging technique for evaluation 
of the knee joint $[3,4]$. In most cases, MRI is performed in the diagnostic work-up of persistent traumatic knee complaints in search of treatable lesions, in particular meniscal tears. MRI, therefore, is usually applied as a triage test for targeted therapeutic arthroscopy [5-7].

Little is known about the appearance of meniscal lesions on follow-up MRI after conservative treatment and its correlation with clinical outcome. Several previous studies have reported on follow-up MRI after surgical meniscal repair [8-10], but in a recent systematic review of the literature, Boks et al. [11] found only one small study on the natural course of meniscal lesions evaluated by sequential MRI [12].

The purpose of this study was to evaluate the natural course of meniscal lesions on structured follow-up MRI in the general practice population, to identify prognostic factors at baseline for meniscal status change after 1 year, and to assess the association of follow-up MRI findings with clinical outcome.

\section{Materials and methods}

Patient selection and study design

We studied a subgroup of the prospective observational HONEUR knee cohort study into acute and chronic knee complaints in primary care in which 1,068 adult and adolescent patients were included. The study design of this cohort was described in detail by Heintjes et al. in a previous paper [13]. The subgroup consisted of consecutively included patients aged 18 to 65 years who visited the general practitioner because of acute knee trauma within the preceding 5 weeks [14]. Exclusion criteria were: severe trauma necessitating immediate hospital referral, a fracture demonstrated radiographically and MRI contraindications. The study was approved by the institutional review board of Maasstad Ziekenhuis, Rotterdam, the Netherlands, and each patient provided written informed consent.

Patients underwent initial MRI within 3 to 6 weeks of trauma and follow-up MRI after approximately 12 months.
Immediately following both MRI examinations, an experienced physiotherapist (HW) performed standardised physical examination, blinded for MRI findings, which included specific meniscal provocation tests.

At baseline and 12 months after trauma self-reported questionnaires were completed, recording a pain score measured on an 11-point numeric rating scale ranging from 0 (no pain) to 10 (unbearable pain) [15], Lysholm knee function score [16], interval injuries, specialist referral and whether or not an operation had been performed. At 12 months we also recorded perceived recovery measured on a seven-point Likert scale, ranging from 'completely recovered' to 'worse than ever'.

\section{MRI technique and interpretation}

MRI examinations were performed on a 1.0-T whole-body MRI unit (Signa Horizon LX, GE Medical Systems, Milwaukee, USA) and a dedicated knee coil. We used an MR imaging protocol as described in Table 1.

The anterior and posterior horns of both menisci were scored separately for tears or degenerative lesions using the grading system listed in Table 2 . We also assessed the presence or absence of coexistent cruciate ligament lesions. Two independent readers (one senior radiology resident (SB) and one experienced musculoskeletal radiologist (DV)) assessed the initial MRI examinations and three independent readers (two senior radiology residents (EHGO and IMK) and one experienced musculoskeletal radiologist (JHH)) evaluated the follow-up MRI using a standardised case report form. In the case of discrepancies, consensus was reached through discussion or the majority opinion was used for analysis. MRI readers were blinded to findings on physical examination, pain scores and functional scores as reported on the questionnaires, but to reflect clinical practice, the initial MRI examination was available for comparison on follow-up MRI interpretation. Unless there were abnormalities that required immediate attention (e.g. fractures or tumours), initial MRI findings were not reported to the general practitioner. Hence, the treatment strategy was not influenced by the MRI findings.

Table 1 Parameters of the MR imaging protocol

\begin{tabular}{|c|c|c|c|c|c|c|}
\hline Sequence & $\begin{array}{l}\text { Plane of } \\
\text { imaging }\end{array}$ & $\begin{array}{l}\text { Repetition } \\
\text { time (ms) }\end{array}$ & Echo time (ms) & $\begin{array}{l}\text { Section } \\
\text { thickness (mm) }\end{array}$ & Matrix & $\begin{array}{l}\text { Field of } \\
\text { view (mm) }\end{array}$ \\
\hline T1-weighted fast spin echo & Sagittal & 575 & 15 & 3 & $384 \times 224$ & $180 \times 135$ \\
\hline Intermediate-weighted fast spin echo & Sagittal & 3,600 & 12 & 3 & $512 \times 224$ & $180 \times 135$ \\
\hline T2-weighted fast spin echo & Sagittal & 3,600 & 100 & 3 & $512 \times 224$ & $180 \times 135$ \\
\hline $\mathrm{T} 2$ gradient echo $^{\mathrm{a}}$ & Coronal & 325 & 14 & 3 & $256 \times 192$ & $180 \times 135$ \\
\hline T2-weighted fat-suppressed fast spin echo & Coronal & 3,700 & 80 & 3 & $384 \times 224$ & $180 \times 135$ \\
\hline Intermediate-weighted fast spin echo & Axial & 3,500 & 15 & 3 & $320 \times 256$ & $170 \times 127.5$ \\
\hline
\end{tabular}

${ }^{\mathrm{a}}$ The flip angle was $30^{\circ}$ 
Table 2 Grading system of meniscal lesions

\begin{tabular}{ll}
\hline Grade 0 & Normal meniscal horn \\
Grade 1 & Focal increased signal intensity within the meniscus \\
Grade 2 & Linear band of increased signal intensity not extending to the articular surface \\
Grade 3 & Horizontal meniscal tear \\
Grade 4 & Longitudinal or vertical meniscal tear \\
Grade 5 & Complex meniscal tear with a combination of multiple cleavage planes
\end{tabular}

For this study, grade 1 and 2 lesions were considered degenerative abnormalities. Signal abnormality extending to the articular surface was used as a criterion for diagnosing a meniscal tear

In the case of referral to a specialist, the specialist was able to request the initial MRI report so as to avoid unnecessary repetition of an MRI examination.

\section{Data analysis}

Patients who underwent an operation during the follow-up period were excluded from the analysis. We performed permeniscal horn univariate and multivariate ordinal logistic regression analysis using Stata/SE 10.0 for Windows (StataCorp, College Station, Texas, USA) with the separately available user-written Gologit2 macro [17]. As the three possible ordinal outcomes, we defined an improved, unchanged and deteriorated meniscal appearance as reflected by the grading difference on follow-up versus initial MRI. Performing ordinal logistic regression analysis with three possible outcomes, two regression equations are estimated with two regression coefficients per independent variable. The first coefficient contrasted an unchanged or deteriorated with an improved meniscal appearance, and the second coefficient indicated a deteriorated versus an unchanged or improved meniscal appearance.

The following independent variables were analysed: age (continuous and dichotomised at age 40), sex, physique as measured by body weight and body mass index (continuous and dichotomised at 25 and $30 \mathrm{~kg} / \mathrm{m}^{2}$ ), sports injury as the trauma mechanism, baseline pain score (continuous and dichotomised at 6 points), Lysholm knee function score (continuous and dichotomised at 50 points), presence of a degenerative or traumatic meniscal lesion on baseline MRI, a complete ACL rupture on the initial MRI and three dummy variables to code the four meniscal horns so as to assess the effect of location. We also evaluated pain at passive flexion during initial physical examination, as this was the only variable from physical examination to show an association with meniscal tears in a previous study [18].

Variables with a $p$ value of less than 0.10 in the univariate analysis were included in the multivariate analysis. In the multivariate analysis, a $p$ value of less than 0.05 was considered statistically significant.

We used the mean values of the other patients to impute missing data on baseline pain score and Lysholm knee function score in three patients and on pain score and perceived recovery in seven and one patients, respectively. As sports injury was strongly correlated with age and sex, we performed a logistic regression analysis with these variables to impute missing data on sports injury in six patients. It has been demonstrated that imputation of missing data reduces the risk of bias and is preferable over complete case analysis $[19,20]$.

We assessed the association between change of meniscal MRI appearance and clinical outcome, as indicated by perceived recovery and change in pain score at 12 months versus baseline. As these variables were recorded on a patient level, we first created an overall variable, reflecting per patient whether or not meniscal deterioration was seen in any of the horns on follow-up. We assumed that the rating of clinical outcome is determined by the meniscal horn with the least favourable change. Thus, a patient with improvement of one meniscal horn and deterioration of another horn on follow-up MRI was coded as deteriorated in the overall variable. Subsequently, we analysed the association between meniscal deterioration on a per-patient level and perceived recovery and change in pain score using Fisher's exact test.

Because the exact procedure and effect on meniscal MRI appearance was unknown in some patients who underwent surgery, and to explore the effect of possible selection bias, we performed a sensitivity analysis including the operated patients.

As four meniscal horns per patient were analysed separately, we corrected for the clustered nature of the data using bootstrapping when testing for statistical significance. Bootstrapping was performed by creating 1,000 replications of the dataset using sampling with replacement and treating all of a patient's observations as a cluster (implying an independent identical distribution at the patient level) [21]. Bias-corrected 95\% confidence intervals are reported.

\section{Results}

Of 263 potentially eligible patients, 134 fulfilled the inclusion criteria and agreed to undergo additional MRI 
and physical examination at baseline. Follow-up MRI and physical examination were performed in 117 patients. Seventeen patients were not followed up because they refused follow-up MRI and physical examination, or because they had moved and we were unable to contact them. A diagram indicating the patient selection and flow through the study is presented in Fig. 1. Fifteen patients were excluded from the analysis because they reported having undergone surgery (14 arthroscopies and one ACL reconstruction) during follow-up. The exact type of arthroscopic procedure, however, was not always known. Another patient was excluded because postoperative findings associated with a partial meniscectomy of the anterior horn of the lateral meniscus were unequivocally present on follow-up MRI, although data on the procedure were missing on the questionnaires. In one patient, only the posterior horn of the medial meniscus was excluded because of partial meniscectomy before the start of the study. Thus, a total of 403 meniscal horns in 101 patients (59 male, 42 female; mean age 40, range 18-63 years) were analysed. Mean time between MRI examinations was 404 days (standard deviation 59.1, range 315-675 days).

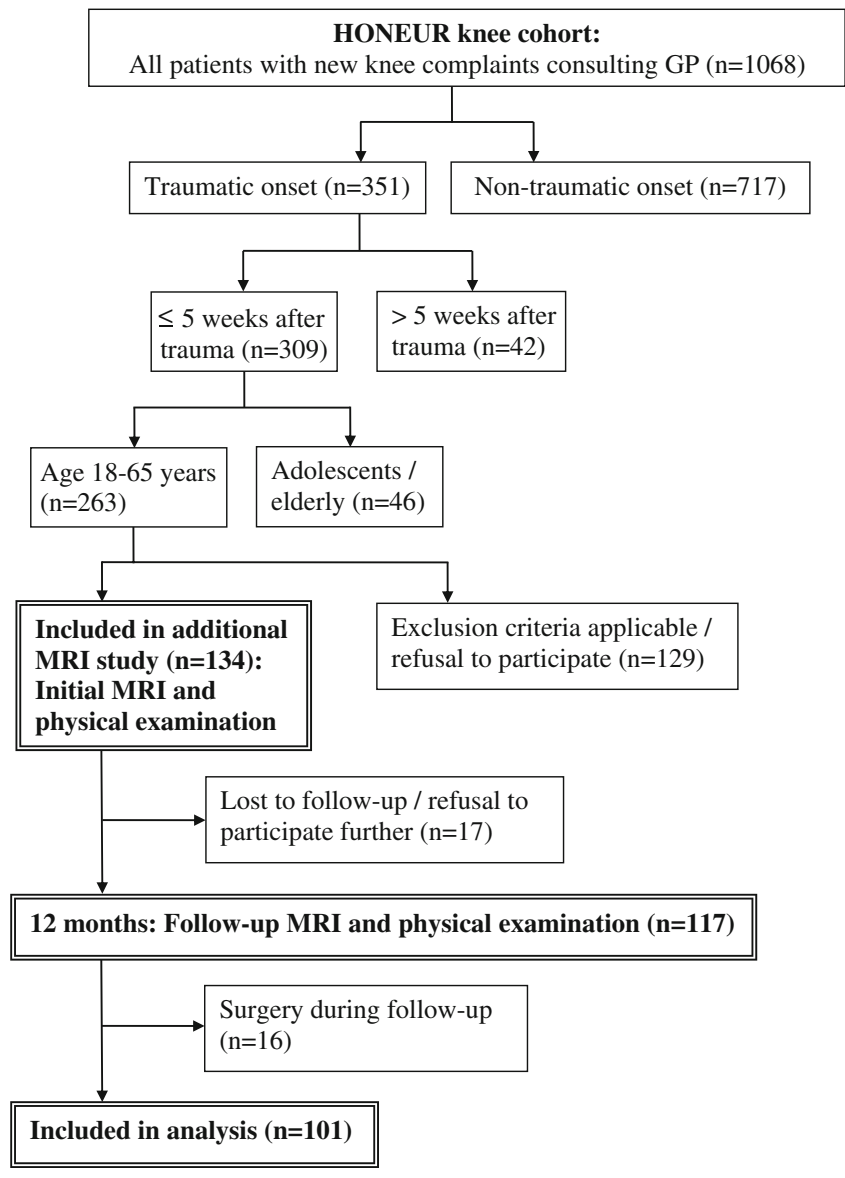

Fig. 1 Flow diagram indicating the selection of subjects and the flow of patients through the study
There were no patients reporting a substantial knee injury between baseline and follow-up MRI.

At baseline, there were 50 tears and 122 degenerative lesions in 403 meniscal horns, most frequently in the posterior horn of the medial meniscus (24 tears and 51 degenerative lesions). In nine patients a complete ACL rupture was diagnosed on initial MRI, while no posterior cruciate ligament tears were seen. The change in meniscal MRI appearance after a 1-year follow-up is presented in Table 3. A total of 336 meniscal horns (of which 231 were normal) remained unchanged after 1 year. Twenty-seven initially normal meniscal horns showed progression to a degenerative lesion, but not into a tear. Six initially degenerative lesions were scored as frank tears on followup MRI, all of which were horizontal. Three new meniscal tears, also exclusively of the horizontal type, were seen on follow-up MRI without pre-existing abnormalities initially. Eight meniscal tears showed progression and developed into complex tears. On the other hand, eight degenerative lesions and one horizontal tear on initial MRI were classified as normal on follow-up MRI. Five initial meniscal tears no longer extended to the articular surface on follow-up MRI and were thus classified as a degenerative lesion. Two initially complex meniscal tears showed improved morphology on follow-up. Figure 2 shows an example of an initially normal anterior horn of the lateral meniscus in which a degenerative lesion had developed on follow-up MRI.

Table 4 presents the results of the univariate ordinal logistic regression analysis for meniscal deterioration versus improvement on follow-up MRI. Age (both continuous and dichotomised at 40 years), baseline pain score 6 points or higher, a meniscal lesion on initial MRI, complete ACL rupture on initial MRI and location in the posterior horn of the medial meniscus were statistically significant predictors of change in meniscal appearance after 1 year, and were included in the multivariate ordinal logistic regression analysis. We also included body weight (continuous) as it was of borderline significance when analysed univariately $(p=0.10)$. Baseline pain score was no longer statistically significant when controlling for the other variables and was therefore excluded from the final multivariate model (Table 5). In the sensitivity analysis of 117 patients including the 16 operated patients, we identified the same significant variables as above with similar odds ratios and confidence intervals (results not tabulated).

\section{Correlation with clinical outcome}

Regarding perceived recovery at 1 year, 28 and 67 patients reported complete recovery and improvement, respectively, whereas 2 patients experienced some deterioration. There were no patients reporting substantial deterioration or a condition that was worse than ever. Table 6 presents a cross-tabulation of perceived recovery and meniscal MRI appearance change. Forty-two patients with meniscal 
Table 3 Change in meniscal appearance on follow-up MRI compared with initial MRI

\begin{tabular}{|c|c|c|c|c|c|}
\hline & $\begin{array}{l}\text { Lateral meniscus } \\
\text { anterior horn } \\
(n=101)\end{array}$ & $\begin{array}{l}\text { Lateral meniscus } \\
\text { posterior horn } \\
(n=101)\end{array}$ & $\begin{array}{l}\text { Medial meniscus } \\
\text { anterior horn } \\
(n=101)\end{array}$ & $\begin{array}{l}\text { Medial meniscus } \\
\text { posterior horn } \\
(n=100)\end{array}$ & $\begin{array}{l}\text { Total } \\
(n=403)\end{array}$ \\
\hline \multicolumn{6}{|l|}{ Unchanged } \\
\hline Normal to normal & 56 & 71 & 85 & 19 & 231 \\
\hline Grade 1 to grade 1 & 12 & 9 & 5 & 24 & 50 \\
\hline Grade 2 to grade 2 & 1 & 0 & 3 & 16 & 20 \\
\hline Horizontal tear to horizontal tear & 5 & 6 & 2 & 10 & 23 \\
\hline Vertical tear to vertical tear & 3 & 0 & 1 & 7 & 11 \\
\hline Complex tear to complex tear & 1 & 0 & 0 & 0 & 1 \\
\hline \multicolumn{6}{|l|}{ New degenerative lesions and tears } \\
\hline Normal to grade 1 (new) & 11 & 7 & 2 & 5 & 25 \\
\hline Normal to grade 2 (new) & 2 & 0 & 0 & 0 & 2 \\
\hline Normal to horizontal tear & 2 & 0 & 0 & 1 & 3 \\
\hline \multicolumn{6}{|l|}{ Progression of lesion complexity } \\
\hline Grade 1 to grade 2 & 0 & 1 & 0 & 4 & 5 \\
\hline Grade 1 to horizontal tear & 1 & 0 & 0 & 0 & 1 \\
\hline Grade 2 to horizontal tear & 1 & 0 & 0 & 4 & 5 \\
\hline Horizontal tear to complex tear & 0 & 3 & 0 & 2 & 5 \\
\hline Vertical tear to complex tear & 3 & 0 & 0 & 0 & 3 \\
\hline \multicolumn{6}{|l|}{ Improvement of lesion complexity } \\
\hline Grade 2 to grade 1 & 0 & 1 & 1 & 1 & 3 \\
\hline Horizontal tear to grade 2 & 1 & 0 & 0 & 1 & 2 \\
\hline Vertical tear to grade 1 & 0 & 0 & 0 & 1 & 1 \\
\hline Vertical tear to grade 2 & 0 & 0 & 0 & 2 & 2 \\
\hline Complex tear to horizontal tear & 0 & 0 & 0 & 1 & 1 \\
\hline \multicolumn{6}{|l|}{ Normalisation of lesions } \\
\hline Grade 1 to normal & 2 & 2 & 1 & 1 & 6 \\
\hline Grade 2 to normal & 0 & 0 & 1 & 1 & 2 \\
\hline Horizontal tear to normal & 0 & 1 & 0 & 0 & 1 \\
\hline
\end{tabular}

Combinations that are not listed in the table were not observed in our study

deterioration on follow-up MRI reported improvement of clinical outcome. Meniscal deterioration was not statistically significantly associated with clinical deterioration measured by perceived recovery (Fisher's exact test $p$ value $0.50)$. Similarly, no statistically significant association was found between meniscal deterioration and an increased pain score at 12 months' follow-up (Fisher's exact test $p$ value 1.0 , results not tabulated).

\section{Discussion}

We studied the natural course of meniscal knee lesions and prognostic factors for meniscal appearance change on follow-up MRI 1 year after trauma. Unlike most published studies on meniscal abnormalities we studied a general practice population, because in our country most patients with traumatic knee injury are managed in primary care. To our knowledge, our study is the first to evaluate the natural course of meniscal abnormalities by using MRI follow-up in a large study population in primary care.

The largest proportion of meniscal horns (57.3\%) were initially normal and remained normal on follow-up, reflecting the primary care setting of this study. It is possible that the proportion of normal menisci was larger than in a hospital setting. We found that new degenerative meniscal signal abnormalities on MRI may develop within 1 year of trauma. Conversely, in a number of menisci initially scored as degenerative, we no longer observed abnormal signal intensity on follow-up, suggesting that smaller areas of intrameniscal signal abnormality may be transient. All new meniscal tears were of the horizontal type, and most of these were degenerative lesions initially. This finding is consistent with previous studies suggesting 

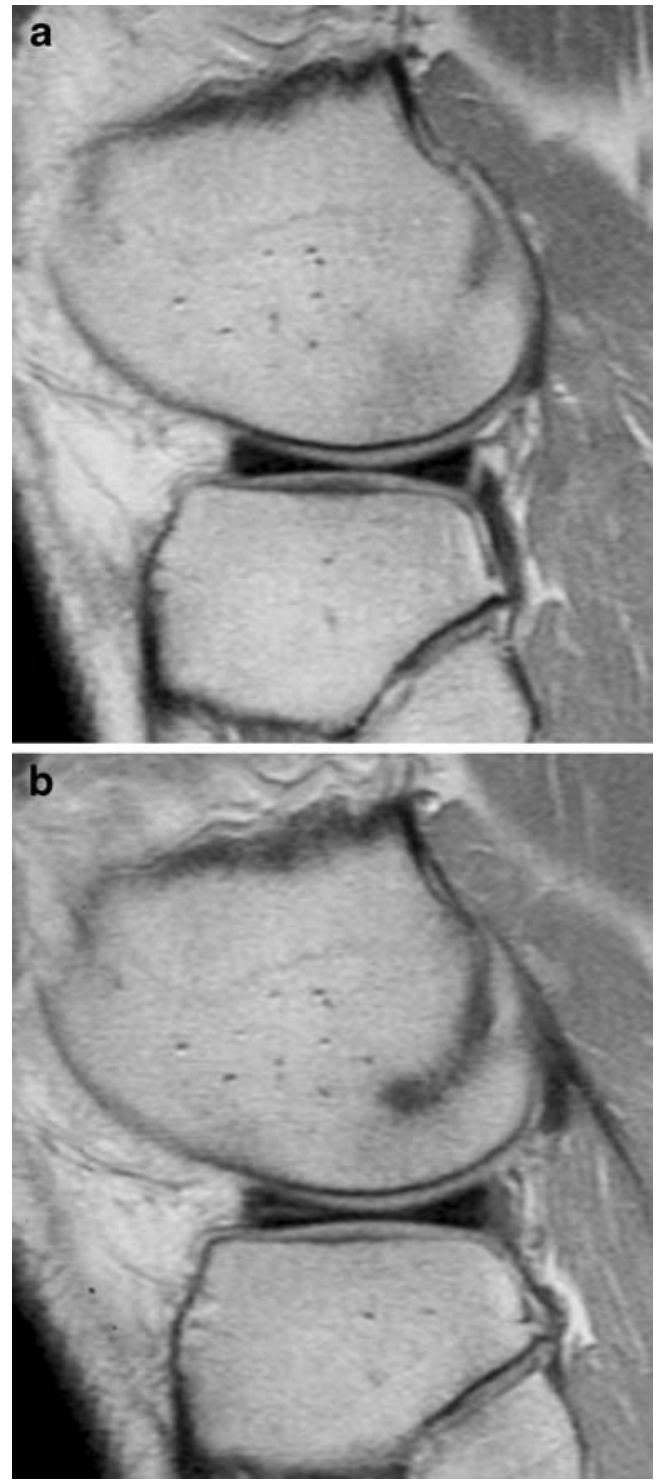

Fig. 2 Development of a degenerative lesion on follow-up MRI in a patient who sustained a distortion of his right knee. a On the initial MRI examination, a normal anterior horn of the lateral meniscus was seen. b Follow-up MRI after 1 year demonstrated a linear band of increased signal intensity that did not extend to the articular surface, which was scored as a grade 2 degenerative lesion

that horizontal tears are usually a manifestation of degenerative disease rather than trauma [22, 23]. It is likely that the new horizontal meniscal tears that were not associated with previous abnormalities developed gradually from normal to a degenerative lesion and subsequently to a degenerative tear over the course of 1 year. Although the number of cases where we found improvement of meniscal tear morphology is relatively small, the findings suggest that natural healing is possible. The natural healing potential of menisci after conservative treatment was also reported previously by Ihara et al. [24], but in this earlier study arthroscopy was used instead of MRI to assess the menisci.

In the multivariate ordinal logistic regression analysis, deterioration of meniscal appearance after 1 year was significantly predicted by higher age and body weight, location in the posterior horn of the medial meniscus, and a total ACL rupture on initial MRI. The last of these findings is consistent with previous studies demonstrating a higher incidence of meniscal tears in ACL-deficient unstable knees $[25,26]$. Presence of a meniscal lesion on initial MRI was also statistically significant, but with an odds ratio smaller than 1, indicating improvement if a meniscal lesion was present initially, and again suggesting a natural healing potential for meniscal lesions. The natural healing tendency is, however, nullified if other predictive factors for deterioration with an odds ratio greater than 1 are present. The results indicate that patients with higher age and body weight, initial total ACL rupture, and a lesion in the posterior horn of the medial meniscus have a high risk of meniscal deterioration 1 year after trauma in contrast to patients without these risk factors who have a relatively good prognosis.

As the HONEUR knee cohort was not aimed at assessing treatment options for knee lesions, the management of our patient population was not documented in detail. Consequently, in some of the 14 patients who underwent arthroscopy, it was unknown what procedure was performed. Although most of these patients probably underwent partial meniscectomy, the most common procedure in the setting of meniscal abnormalities, we were not completely certain which component of MRI appearance change could be attributable to surgery. To overcome this problem and to obtain a homogeneous study population, we only analysed conservatively treated patients. To explore the possible effect of selection bias that may have been introduced because the more severe cases necessitating surgery were not analysed, we performed a sensitivity analysis that included the operated patients. This resulted in an identical multivariate model with similar odds ratios, indicating that our results were not influenced by the exclusion of operated patients.

We also studied the association between change in meniscal MRI appearance and clinical outcome. We found no statistically significant association between meniscal deterioration on follow-up MRI and worse clinical outcome, as reflected by perceived recovery or change in pain score. Many patients with deteriorated meniscal MRI appearance still reported strong improvement or even complete recovery. Our results are consistent with those of Deutsch et al. [12], indicating that meniscal appearance on follow-up MRI does not correlate with clinical outcome, and suggesting that it is not useful to perform follow-up MRI of the menisci to explain clinical deterioration. In light of these results, we acknowledge that an increased score on MRI grading systems based solely on worsened morphology of meniscal signal abnormality, like that used in our 
Table 4 Results of the univariate ordinal logistic regression analysis for meniscal deterioration versus improvement on follow-up MRI

\begin{tabular}{|c|c|c|c|}
\hline Covariable & $\begin{array}{l}\text { Observed frequency in study } \\
\text { population of } 101 \text { patients } \\
\text { (percentage) }^{\mathrm{a}}\end{array}$ & $\begin{array}{l}\text { Odds ratio } \\
\text { (95\% confidence interval) }\end{array}$ & $P$ value \\
\hline Age (continuous) & 40.0 years $(11.8,18-63)^{\mathrm{a}}$ & $1.02 /$ year $(1.00-1.04)$ & 0.03 \\
\hline Age $>40$ years & $48(48)$ & $2.09(1.16-3.76)$ & 0.01 \\
\hline Male sex & $59(58)$ & $0.93(0.58-1.50)$ & 0.78 \\
\hline Body weight & $82.2 \mathrm{~kg}(16.0,40-129)^{\mathrm{a}}$ & $1.01 / \mathrm{kg}(1.00-1.03)$ & 0.10 \\
\hline Body mass index (continuous) & $26.1 \mathrm{~kg} / \mathrm{m}^{2}(4.2,17-40)^{\mathrm{a}}$ & $1.04(0.98-1.09)$ & 0.20 \\
\hline Body mass index $>25$ & $58(57)$ & $1.45(0.89-2.36)$ & 0.13 \\
\hline Body mass index $>30$ & $18(18)$ & $1.35(0.74-2.48)$ & 0.33 \\
\hline Sports injury ${ }^{\mathrm{b}}$ & $53(52)$ & $0.81(0.50-1.30)$ & 0.38 \\
\hline Baseline pain score continuous $^{\mathrm{c}}$ & $4.4(2.2,0-10)^{\mathrm{a}}$ & $0.93(0.85-1.03)$ & 0.17 \\
\hline Baseline pain score $>6$ points $^{\mathrm{c}}$ & $34(34)$ & $0.62(0.36-1.06)$ & 0.08 \\
\hline Baseline Lysholm score continuous $^{\mathrm{c}}$ & $66.8(18.1,18-100)^{\mathrm{a}}$ & $1.00(0.98-1.01)$ & 0.53 \\
\hline Baseline Lysholm score $>50^{\mathrm{c}}$ & $79(78)$ & $1.07(0.64-1.80)$ & 0.79 \\
\hline Pain at passive flexion during physical examination & $62(61)$ & $1.16(0.73-1.84)$ & 0.53 \\
\hline Meniscal lesion on initial MRI & $142 / 403$ horns $(35)$ & $0.48(0.23-0.98)$ & 0.05 \\
\hline Total ACL rupture on initial MRI & $9(9)$ & $1.89(1.12-3.21)$ & 0.02 \\
\hline Location in posterior horn medial meniscus & $100(99)$ & $0.39(0.14-1.07)$ & 0.07 \\
\hline
\end{tabular}

${ }^{\mathrm{a}}$ For continuous variables, we report mean (standard deviation, range)

${ }^{\mathrm{b}}$ Six missing values were imputed

${ }^{\mathrm{c}}$ Three missing values were imputed

study, probably does not correlate with deteriorated clinical meniscal status in many patients.

We used a 1.0-T MRI unit, but it has been shown that lower magnetic field strength does not significantly reduce diagnostic performance for meniscal tears [3]. Moreover, as we studied meniscal lesions over time rather than the diagnostic accuracy of the MRI technique, we expect that this did not influence our results. We cannot completely exclude the possibility of misinterpretation of meniscal appearance change due to slight differences in imaging

Table 5 Results of the multivariate ordinal logistic regression analysis

\begin{tabular}{llll}
\hline Covariable & Odds ratio & $95 \%$ confidence interval & $P$ value \\
\hline No change and deterioration versus improvement & & & \\
Age (continuous, per decade) & 1.33 & $1.07-1.68$ & $0.63-1.15$ \\
Body weight (continuous, per 10 kg) & 0.85 & $0.12-0.72$ & 0.29 \\
Presence of meniscal lesion on initial MRI & 0.30 & $1.14-4.82$ & 0.01 \\
Presence of total ACL rupture on initial MRI & 2.35 & $0.16-3.46$ & 0.02 \\
Location in posterior horn medial meniscus & 0.74 & & 0.70 \\
Deterioration versus no change and improvement & & $1.07-1.68$ & 0.01 \\
Age (continuous, per decade) & 1.33 & $1.01-1.49$ & 0.04 \\
Body weight (continuous, per 10 kg) & 1.22 & $0.12-0.72$ & 0.01 \\
Presence of meniscal lesion on initial MRI & 0.30 & $1.14-4.82$ & 0.02 \\
Presence of total ACL rupture on initial MRI & 2.35 & $1.20-7.40$ & 0.02 \\
Location in posterior horn medial meniscus & 2.98 & & \\
\hline
\end{tabular}

For each independent variable, we first evaluated the applicability of the proportional odds assumption by using Gologit2's 'autofit' option and subsequently specified per variable whether or not the proportional odds assumption was to be applied. This resulted in a partial proportional odds model, with two identical regression coefficients for variables meeting the proportional odds assumption and two different coefficients for those that violated the assumption 
Table 6 Perceived recovery and overall per-patient change in meniscal appearance on follow-up MRI

\begin{tabular}{|c|c|c|c|c|c|c|}
\hline & \multicolumn{6}{|c|}{ Perceived recovery } \\
\hline & $\begin{array}{l}\text { Complete } \\
\text { recovery }\end{array}$ & $\begin{array}{l}\text { Strong } \\
\text { improvement }\end{array}$ & $\begin{array}{l}\text { Some } \\
\text { improvement }\end{array}$ & Unchanged & $\begin{array}{l}\text { Some } \\
\text { deterioration }\end{array}$ & Total \\
\hline MRI appearance improved or unchanged & 12 & 35 & 6 & 2 & 2 & 57 \\
\hline MRI appearance deteriorated & 16 & 22 & 4 & 2 & 0 & 44 \\
\hline Total & 28 & 57 & 10 & 4 & 2 & 101 \\
\hline
\end{tabular}

Table displays number of patients. There were no patients reporting substantial deterioration or a condition that was worse than ever

plane orientation, but in our view the likelihood of misclassification is low because identical pulse sequences were used for initial and follow-up MRI, and in most cases the presence of a meniscal tear was confirmed on multiple contiguous images.

We conclude that the MRI appearance of meniscal lesions 1 year after trauma is variable. In conservatively treated patients, higher age and body weight, total ACL rupture and location in the posterior horn of the medial meniscus predict meniscal deterioration on follow-up MRI after 1 year and, if present, these factors nullify the natural healing potential suggested by our results. There is no association between change in meniscal MRI appearance and clinical outcome, and in many clinically recovered or strongly improved patients, persistent abnormal or deteriorated meniscal appearance is seen.

Acknowledgements The authors thank Ms Wibeke van Leeuwen and Mrs Caroline van Bavel-van Hamburg for their help in the data management.

This study was funded in part by College voor Zorgverzekeringen (Dutch Health Insurance Board).

Open Access This article is distributed under the terms of the Creative Commons Attribution Noncommercial License which permits any noncommercial use, distribution, and reproduction in any medium, provided the original author(s) and source are credited.

\section{References}

1. Van der Linden MW, Westert GP, de Bakker DH et al (2004) Tweede nationale studie naar ziekten en verrichtingen in de huisartspraktijk: klachten en aandoeningen in de bevolking en in de huisartspraktijk. Nivel, Rijksinstituut voor volksgezondheid en milieu, Utrecht, Bilthoven

2. Cardol M, van Dijk L, de Jong JD et al (2004) Tweede Nationale Studie naar ziekten en verrichtingen in de huisartspraktijk. Huisartsenzorg: wat doet de poortwachter? NIVEL/RIVM, Utrecht, Bilthoven

3. Oei EH, Nikken JJ, Verstijnen AC, Ginai AZ, Myriam Hunink MG (2003) MR imaging of the menisci and cruciate ligaments: a systematic review. Radiology 226:837-848

4. Mackenzie R, Palmer CR, Lomas DJ, Dixon AK (1996) Magnetic resonance imaging of the knee: diagnostic performance studies. Clin Radiol 51:251257
5. Ruwe PA, Wright J, Randall RL, Lynch JK, Jokl P, McCarthy S (1992) Can MR imaging effectively replace diagnostic arthroscopy? Radiology 183:335-339

6. Vincken PW, ter Braak BP, van Erkel AR et al (2002) Effectiveness of MR imaging in selection of patients for arthroscopy of the knee. Radiology 223:739-746

7. Vincken PW, ter Braak AP, van Erkel AR et al (2007) MR imaging: effectiveness and costs at triage of patients with nonacute knee symptoms. Radiology 242:85-93

8. Hantes ME, Zachos VC, Zibis AH et al (2004) Evaluation of meniscal repair with serial magnetic resonance imaging: a comparative study between conventional MRI and indirect MR arthrography. Eur J Radiol 50:231-237

9. Mustonen AO, Tielinen L, Lindahl J, Hirvensalo E, Kiuru M, Koskinen SK (2006) MRI of menisci repaired with bioabsorbable arrows. Skeletal Radiol 35:515-521

10. Steenbrugge F, Verstraete K, Verdonk R (2004) Magnetic resonance imaging of the surgically repaired meniscus: a 13year follow-up study of 13 knees. Acta Orthop Scand 75:323-327
11. Boks SS, Vroegindeweij D, Koes BW, Hunink MG, Bierma-Zeinstra SM (2006) Follow-up of posttraumatic ligamentous and meniscal knee lesions detected at MR imaging: systematic review. Radiology 238:863-871

12. Deutsch AL, Mink JH, Fox JM et al (1990) Peripheral meniscal tears: MR findings after conservative treatment or arthroscopic repair. Radiology 176:485-488

13. Heintjes EM, Berger MY, Koes BW, Bierma-Zeinstra SM (2005) Knee disorders in primary care: design and patient selection of the HONEUR knee cohort. BMC Musculoskelet Disord $6: 45$

14. Boks SS, Vroegindeweij D, Koes BW, Hunink MM, Bierma-Zeinstra SM (2006) Magnetic resonance imaging abnormalities in symptomatic and contralateral knees: prevalence and associations with traumatic history in general practice. Am J Sports Med 34:1984-1991 
15. Herr KA, Spratt K, Mobily PR, Richardson G (2004) Pain intensity assessment in older adults: use of experimental pain to compare psychometric properties and usability of selected pain scales with younger adults. Clin J Pain 20:207-219

16. Briggs KK, Kocher MS, Rodkey WG, Steadman JR (2006) Reliability, validity, and responsiveness of the Lysholm knee score and Tegner activity scale for patients with meniscal injury of the knee. J Bone Jt Surg Am 88:698-705

17. Williams R (2006) Generalized ordered logit/partial proportional odds models for ordinal dependent variables. Stata J 6:58-82
18. Wagemakers HP, Heintjes EM, Boks SS et al (2008) Diagnostic value of history-taking and physical examination for assessing meniscal tears of the knee in general practice. Clin J Sport Med 18:24-30

19. Van der Heijden GJ, Donders AR, Stijnen T, Moons KG (2006) Imputation of missing values is superior to complete case analysis and the missingindicator method in multivariable diagnostic research: a clinical example. J Clin Epidemiol 59:1102-1109

20. Schafer J (1997) Analysis of incomplete multivariate data. Chapman \& Hall, London

21. Efron B, Tibshirani RJ (1993) An introduction to the bootstrap. Chapman \& Hall, New York

22. Bhattacharyya T, Gale D, Dewire P et al (2003) The clinical importance of meniscal tears demonstrated by magnetic resonance imaging in osteoarthritis of the knee. J Bone Jt Surg Am 85-A:4-9
23. Lange AK, Fiatarone Singh MA, Smith RM et al (2007) Degenerative meniscus tears and mobility impairment in women with knee osteoarthritis. Osteoarthritis Cartilage 15:701-708

24. Ihara H, Miwa M, Takayanagi K, Nakayama A (1994) Acute torn meniscus combined with acute cruciate ligament injury. Second look arthroscopy after 3-month conservative treatment. Clin Orthop Relat Res 307:146-154

25. Daniel DM, Stone ML, Dobson BE, Fithian DC, Rossman DJ, Kaufman KR (1994) Fate of the ACL-injured patient. A prospective outcome study. Am J Sports Med 22:632-644

26. Nebelung W, Wuschech H (2005) Thirty-five years of follow-up of anterior cruciate ligament-deficient knees in high-level athletes. Arthroscopy 21:696-702 